\title{
KLHL9-related early-onset distal myopathy
}

INSERM

\section{Source}

INSERM. (1999). Orphanet: an online rare disease and orphan drug data base. KLHL9related early-onset distal myopathy. ORPHA:399081

KLHL9-related early-onset distal myopathy is a rare, genetic distal myopathy characterized by slowly progressive distal limb muscle weakness and atrophy (beginning with anterior tibial muscle involvement followed by the intrinsic hand muscles) in association with reduced sensation in a stocking-glove distribution. Patients present with high stepping gait, ankle areflexia and contractures in the first to second decade of life, associated with marked ankle extensor muscle atrophy; later proximal muscle involvement is moderate and ambulation is preserved throughout the life. 